\title{
A REFORMA do JURY NO SENADO DE SÃo PAULO
}

\author{
1924
}

Art. 2. - "Não scrî́ permittida a presença do publico no julgamento dos crimes previstos no titulo VIII, c(l). 1. do Cod. Penal."

(Projecto da Camara dos Deputados).

O Sr. Candido Motra (movimento de attenção.) Sr. presidente, não sou, como $V$ Exc. bem sabe, signatario do parecer da commissão de justiça sobre o projecto em discussão, mas, desse facto todo accidental, resultaram para mim consequencias um tanto desagradaveis e devéras penosas.

A primeira dellas foi dar logar á supposição de uma divergencia no seio da commissão de que tenho a honra de fazer parte; a segunda foi esta de me obrigar a vir á tribuna para justificar o meu voto contra o projecto, quando, solidario com os meus honrados collegas, não o poderei fazer melhor do que o fizeram elles.

Eis porque apresso-me em vir tornar bem claros o meu pensamento e a minha attitude em relação ao assumpto, correspondendo assim ao appello, quasi nominal, que me foi dirigido das columnas do Jornal do Commercio. desta capital, pelo meu eminente collega, o professor dr. João Arruda, incontestavelmente uma das glorias do ma. gisterio superior da Republica. (Muito bem.) 
Sob o titulo - Publicidade de Julgamento - escreveu o illustre professor o interessante trabalho com que se dignou me interpellar.

Começo por não achar feliz aquelle titulo, visto não corresponder com precisão ao objecto em litigio.

Não se trata, como poderá parecer á primeira vista, da publicidade de julgamentos proferidos pelo Jury.

O projecto de tal não cogita.

Approvado elle, o julgamento pelo jury continuará, como até aqui, inteiramente secreto. A controversia deve recahir, como de facto recae, exclusivamente sobre a PUBLICIDĀDE DOS DEBATES, em certos e determinados casos, ou melhor, nos casos comprehendidos no Cap. 1., tit. VIII do Codigo Penal, materia essa que faz objecto do art. $2 .^{\circ}$ do projecto.

Não sou, nem fui jamais partidario da instituição do jury, que illustre publicista patrio denomina - simples mystificação elevada imprudentemente á altura de uma garantia constitucional - e que um relatorio da AMerICan Bar Association, de 1886, assim descreve:

"Este systema consiste em tomar uma equipagem de doze homens: um legista, um medico, um sacerdote, um negociante, um banqueiro, um lavrador, um carpinteiro, um sapateiro, um rendeiro, um vagabundo, um taverneiro e um astronomo. Collocae esta equipagem variegada sob a direcção de um habil marinheiro, mas que não conheça ainda o navio; largae tudo, e fiae-vos na Divina Providencia!"

Dos Annaes da Camara dos Deputados constam discursos meus, nos quaes fiz sobre o assumpto em debate a minha profissão de fé.

A esse tempo, como agora, descrente da instituição do jury como instrumento efficaz dia defeza social contra o crime, mesmo porque, no dizer de Jules Dillon, as boas 
causas se pleiteam perante os juizes e as más perante o Jury - propuz a restricção da sua competencia aos crimes de morte, roubo, furto etc., passando para o julgamento do juiz singular e togado, entre outros, os crimes de que cogita $o$ art. $2 .^{\circ}$ do actual projecto.

Fui vencido, por entender a maioria da Camara que a expressão constitucional fica mantida a instituição do jury - nos tolhia o direito de lhe diminuir as attribuições, a competencia que tinha ao promulgar-se o nosso pacto fundamental.

Ora, si assim é, esse o pensamento ainda hoje dominante não ha razão para que eu venha insistir no assumpto e procurar perturbar, com o meu modo pessoal de ver, uma doutrina pacifica entre os mais competentes.

Direi até, com o grande professor Eurico Ferri, um dos mais pertinazes adversarios da instituição do Jury, em seus "Studi di giurisprudenza", pag. 40l: (lê)

"Ma fincché il giuri esiste per legge, noi crediano ch'esso debba liberamente funzzionare, e che come furano incostituzionale le restrizzione di competenza imposte dal decreto nelle transitorie, cosi sono illogiche e pericolose le restrizione di giudizio"

Mas, pergunta-se, a publicidade dos debates essencia da instituição do jury? Entendo que sim. 0 art. 288 do Codigo de Processo Criminal, que ainda nos rege, é expresso: (lê)

"As sessões dos jurados SERÃo TODAS PUBLICAS, excepto quando houver votação; mas, ninguem assistirá a ellas com armas, etc."

Essa é, dirão, uma lei de processo; e os Estados, podendo legislar a respeito, poderão alteral-a profundamente.

Não direi por minha vez, porque, embora a materia esteja regulada em lei de processo, ella affecta a propria 
essencia da instituição do jury, tal como a concebeu o legislador constituinte.

Mas, replicar-se-á, é essa justamente a questão; contestamos que tal publicidade seja um caracter fundamental da instituição.

Pois vejamos si o é, eștudando o jury nas suas remotas origens, atravez diversos povos, aproveitando, para isso, alem de outros, o magnifico trabalho do dr. Pinto da Rocha - O jury e a sua Evolução.

$\mathrm{Na}$ lei mosaica, a informação rigorosia para a elucidação da causa, antes da pronuncia e do plenario, A PUBLICIDADE DOS DEBATES etc. são formalidades e garantias da jurisprudencia moderna, que já eram conhecidas dos hebreus e por elles religiosamente respeitadas.

Toda processualistica criminal de Moysés assenta em quatro regras, que podem ser synthetizadas nestas palavras: informação rigorosa, PUBLICIDADE DOS DEBÁTES, liberdade de defesa, garantia contra o perigo dos testemunhos.

Uma passagem bem conhecida, um principio perfeitamente reproduzido nas escripturas hebraicas, resume as duas condições de liberdade e publicidade. Jeovah, o eterno, apresenta-se como um espirito de extremado adepto dos debates contradictorios. "Discutamos, discutamos juntamente e em PlËNA PUbLICIDADE, exclama elle; em todas as circumstancias, debatamos os nossos direitos."

No dia marcado para um julgamento, comparecia o accusado. Os anciãos da cidade reuniam-se publicamente. ao ar livre e á sombra das arvores. A seus pés, os candidatos e auditores seguiam com regularidade todos os debates judiciarios e administrativos. As condições essenciaes, emfim, que a lei mosaica considerava para a boa distribuição da Justiça eram: a PUblicidade Dos DEBATEs e Juizes não estipendiados. 
Entre os povos barbaros, a publicidade absoluta dos julgamentos excluia a possibilidade de qualquer formula secreta. A mais completa publicidade presidia a todo processo, que era feito in presœti populo, como determinava a lei salica. A multidão acudia por tal forma que Carlos Magno viu-se obrigado a prohibir o accesso aos clerigos, aos monges e ás mulheres.

Uma ordenação de Luis Hutin, em 1315, prescrevia a maior publicidade para todas as causas criminaes.

$\mathrm{Na}$ Grecia, o Areopago, que tambem julgava ao ar livre, funccionava á noite, com receio, na opinião de alguns, de que os juizes se deixassem seduzir pela presença dos accusados. Deu logar a este procedimento o julgamento de Phrinéa, que corrompeu os seus juizes, desnudando aos seus olhos a divina belleza dos seios de jaspe (Riso)

Assim como o legislador do decalogo prescrevia que o accusado fosse julgado aos olhos da nação pelos anciãos, que se reuniam á luz do sol, á sombra das arvores, com a MAXIMA PUBlicidade dos Debates, sendo motivado, em succinta exposição, o voto contrario ou favoravel dos juizes, assim na Grecia não se conhecia o sigillo; o julgamento se fazia na praça publica á luz do sol; e dessas circumstancias provem o facto de serem os juizes do tribunal julgador conhecidos pelo nome de heliastas.

Em brilhante prefacio ao já citado estudo do dr. Pinto da Rocha, Carvalho Mourão, cerebro privilegiado, um dos mais solidos e scintillantes espiritos da minha geração academica, assignala: (lê)

"Caracteres essenciaes do Jury são, comı você bem o demonstra: a PUBLICIDAde AMPLA Dos DEBATEs e do julgamento e o processo oral em toda largueza da mais livre discussão." 
Em Roma, segundo Normand, em seu tratado elemental de Direito Criminal, pag. 48, para o processo e repressão das infacções, houve uma orgdnização judiciaria, que variou segundo os casos e as epocas, e jurisdicçóes criminaes, conhecidas, umas sob a denominação de quostiones perpetuae, e outras sob a denominação de cognitiones extraordinariae.

O processo das primeiras ou justitia publica repousava sobre quatro idéas ESSENCIAES, das quaes umas se afastam e outras, ao contrario, se approximam das nossas ideas modernas:

1. O direito de accusação para todos os cidadãos, salvo para os declarados incapazes e indignos:

2. 0 processo oral;

3. A PUBlicidade DOS DEBATES;

4. O julgamento por jurados.

Tal ordo judiciarius soffreu, porem, modificação por parte de Deocleciano, devido aos maus resultados colhidos pela cognitio extraordinaria; modificação essa que deu logar a tres principios novos em materia criminal:

a) 0 direito de appellação para o tribunal do principe; (Sacrum auditorium)

b) A intervenção do magistrado na inquisitio;

c) A reducção, a escripto, de todas as provas.

Como se vê, a publicidade dos debates não sofffreu alteração alguma.

$\mathrm{Na}$ Inglaterra, que passa por ser o verdadeiro berço da instituição do jury, a cousa não tem outra feição.

Em seus estudos sobre as instituiçóes politicas e sociaes da Inglaterra, Theodoro Harcher, antigo professor da Real Academia militar de Woolvich, assim se exprime: (lê) "Na Inglaterra, jamais se julgam os processos de portas fechadas; o juiz quando muito, pode concitar as senhoras a se retirarem, quando elle julga que os DEPOIMENTOS vão versar sobre alguns detalhes escabrosos. A 
verdade nos obriga a confessar que esta injunç̧ão é frequentemente recebida com extrema repugnancia car cela fait toujours passer une heure ou deux (Riso) "Foi preciso uma ordem das mais formaes para fazer com que as mulheres de Dublin renunciassem a audição da narrativa feita pelo major Yelverton da sua aventura á bordo de um navio, aventura que crer-se-ia destacada de uma pagina de Fanblas.

"O ultraje aos bons costumes e á moral publica, como dizem os requisitorios francezes, não parece bastante grave aos inglezes para arriscar o inconveniente de um julgamento occulto.

"Pensamos como elles e, na nossa opinião, a Camara dos Communs recusou-se mui sabiamente a votar a proposta de um membro pudibundo, que pedia o fechamento das portas do tribunal de divorcios.

"Para um povo como para um individuo o perigo da infracção é bem mais imminente, quando se lhe accentam os symptomas do mal."

$\mathrm{Na}$ França, segundo nos informa Maxime du Camp em seu interessantissimo estudo - Paris, ses organes, ses fonctions et sa vie, pag. 171 e seguintes, nada vemos de melhor.

"Em Pariz diz elle, em que as distancias são enormes, as sessões do jury não começam antes das dez e meia.

São, em regra, pouco frequentadas; a parte do recinto reservada, ao publico é muito acanhada e só é occupada pelos que não têm affazeres ou por gatunos, que alli vão estudar in natura os mysterios do Codigo Penal; mas, quando é annunciado um processo importante, todos os logares são bem cedo invadidos; vae-se alli como que a uma representação extraordinaria, como a um drama, cujos heroes, longe de recitar phrases de convenção, lu- 
ctarão para defender a propria vida com um desenlace que nada tem de facticio.

Nestes casos, as mulheres, as da melhor sociedade, misturadas com pequenas burguezas çuriosas, se introduzem sorridentes por entre os bancos das testemunhas, se insinuam perto dos advogados e, tomariam de assalto até a cadeira do presidente, si lh'o permitissem.

E' desagradavel vel-as; e a pretensa sensibilidade, que gostam de ostentar, bem difficilmente se acommoda com a curiosidade tão ardente e malsã que revelam.

Algumas vezes teem que se haver com magistrados de humor pouco accommodaticio.

Recordamo-nos das bellas palavras de um conselheiro que, presidindo o jury, em um processo mui escabroso e vendo um grande numero de mulheres installadas no pretorio, disse: "A causa que vamos julgar contem detalhes inconvenientes, por isso, convido as honestas senhoras aqui presentes a se retirarem."

Ninguem se moveu. Elle, então, continuou: "Sr. official, uma vez que as senhoras honestas já se retiraram, faça sahir as outras." (Riso)

Sob o ponto de vista da curiosidade indecente, as advertencias dos dias 28, 29 e 30 de Dezembro de 1869 , do processo Troppmann, constituiram um verdadeiro es. candalo. A sala estava repleta; todos os logares invadidos; a atmosphera, pesada e quente, parecia a de uma estufa; as raparigas celebres do demi-monde parisiense, as actrizes em voga, se tinham infiltrado por entre os advogados e o corpo dos jurados, que não eram do processo."

"Os Debates, diz ainda o mesmo auctor, pags. 178, SÃo, NÃo só PUBLICOS, contraditorios, mas, quando o processo é escandaloso, é julgado de portas fechadas. Logo depois da leitura do processo, o advogado geral requer a retirada do publico, que só volta quando o presidente começa a fazer o resumo dos debates." 
Sim; o publico não assiste ás tiradas dramaticas ou melodramaticas do Ministerio Publico e da defesa, os detalhes da questão. Mas, de que serve isso, si a substancia não lhe é subtrahida com a audição da leitura do processo e com o resumo dos debates, peça que um illustre magistrado definiu como sendo "o mais difficil esforço que se pode impor á intelligencia e á consciencia de um homem de bem" -- porque, si não reproduz com precisão os detalhes, põe, muitas vezes, em evidencia a parcialidade, mesmo involuntaria, do presidente do Tribunal?

E' por isso que Puglia, em seu Tratado de Processo Penal, pags. 228, etc. diz: (lê)

"A lei, quando fala em debate não limita de fórma alguma, o sentido de tal palavra, razão pela qual surgiu a questão de saber si, tratando. se do Jury, o resumo dos debates deve tambem ser feitos de portas fechadas. Alguns sustentam a affirmativa, porque, aO FAzEr o RESUMO, o PRESIDENTE DEVE TORNAR CONHECIDOS AQUELLES Factos Pelos QUaEs JUSTAMENTE SE ORDENOU o FECHAMENTO DAS PORTAS."

A abolição do resumo dos debates, como bem observa Guarnieri Ventimiglia em um interessante estudo sobre a reforma do jury, é a necessidade mais geralmente sentida por todos quantos teem a pratica do Jury. Aquelle presidente, que resume brevemente a discussão e chama a attenção dos jurados para os principaes argumentos adduzidos pró e contra o accusado é um personagem imaginario ou ideal, que o legislador suppõe no art. 498 do Codigo do Processo, mas que, na pratica, nunca existiu e nem pode existir. E explica: (lê)

"Non é possibile sdoppiare la coscienza del magistrato, costituirne una apposita ai fini della formazione del riassunto, togliere tutto quel cumulo de impressioni, di giudizi e 
de desideri che ha giá costituito una salda convinzione ed impone una linea di condotta alla quale non é umano resistere, perché non é umano sdoppiari ed elevarsi giudice dei propri sentimenti e delle proprie idee.

Il presidente, come qualsiasi uomo, é condotto a transfondere nelle proprie parole la propria opinione, e questa é destinata ad esercitare una grandissima influenza sull, animo dei giurati. Anzi - sembra un paradosso, ma é realtá essendo la convinzione della reitá frequentissima e quasi costante nel presidente del-assise, e rispecchiandola fedelmente il riassunto finale, la semplicitá e la serenitá della parola presidenciale riesce pericolosissima, e, spesso, la difesa desidera uno di quei, , non rari eocesso di zelo per cui il capo del collegio diventando un Publico Ministero - "piú vero e maggiore - possa riuscire sospetto e destare la reazione nel'animo dei giurati

Ouçamos o grande Julio Favre: (lê)

"Tenho ouvido se dizer muitas vezes que o segredo do processo é indispensavel á repressão, e que é mesmo preciso para o accusado. Estão ahi dois sophismas, e o que me prova que estou com a verdade é que a opinião d'aquelles que querem o segredo do processo é antiga, e que já está golpeada pela publicidade.

"Voltae com effeito a cem annos atraz e ahi vereis esta doutrina applicada com toda força de uma logica inflexivel, quando a sociedade, fortemente organizada, queria tambem defender-se, e acreditava que não o podia fazer sem o sacrificio absoluto da publicidade. E, quando um cidadão suspeitado de um crime ca- 
hia nas mãos da justiça criminal, de publico só havia, em seu julgamento o castigo; elle era cercado de sombra e de mysterio. Quando a liberdade lhe era arrebatada, só a recuperava por um instante quando a justiça lhe cahia em cima. $\mathrm{E}$ podeis percorrer todas as phases do processo que devia soffrer, mesmo no que tinha de mais deshumano e mais terrivel, e encontrareis sempre o accusador e o accusado, á sós, na sombra, um em toda sua pujança, o outro em toda sua fraqueza; e este segredo fatal terminava quasi sempre pela condemnação do innocente! E foram precisos estes grandes escandalos de solemnes exemplos, a opinião de philosophos eminentes, as vozes generosas.que se levantaram a sustentar a causa da humanidade para que, emfim, este dogma detestavel do segundo processo succumbisse. "A revolução de 1789 fel-o desapparecer, coisa immensa! eu o reconheço e dou graças a Deus!

"Quanto a mim, senhores, não ha publicidade de julgamento que baste, e sem ir até a discutir os systemas rivaes, sem indagar si a publicidade absoluta do processo criminal não seria mais vantajosa para a sociedade e para o accusado do que o segredo absoluto, limito-me a fazer notar, quanto á sociedade, que o segredo com que envolve o processo pode muitas vezes conduzil-a ao erro, que a publicidade podia evitar; que, quando a justiça se extravia, não só as prisões se prolongam, mas ainda as existencias mais respeitaveis podem ser inquietadas; por isso mesmo que dispõe de um immenso poder, si tal poder é attingido pelo erro, é incontestavel que poderá produzir males incalculaveis. 
"Não é verdade que, com todos os meios de publicidade de que dispomos, o circulo vaé se cerrando ou se distendendo, sem cessar, ern razão da sua importancia. Não é verdade que o segredo nunca existe? Não existe, porque a lei da discreção não é imposta ás testemunhas, e a testemunha, que sae do gabinete do juiz de instrucção, conversa livremente com todos quantos a cercam, etc. etc." (Discursos parlamentares. vol. 2. ${ }^{\circ}$, pag. 415 e seguintes).

Si com a simples instruç̧ão secreta não é possivel obter-se o segredo, como conseguil-o com o julgamento pelo jury, formado pelo modo que conhecemos?

O senador Bevenger, na sessão de 16 de Janeiro de 1907, chamou a attenção da assembléa para as indiscreções, por vezes mui graves, que se commettem diariamente sobre tudo quanto se passa num gabinete de instrucção. A affirmação de que, em França, a instrucção é secreta, é puramente theorica.

Eu vos pergunto, dizia elle, o que ha hoje de secreto nas instruçōes que se fazem. Quando um individuo é preso, é logo cercado de solicitações dos reporters, e é a custo que os agentes de policia ou os gendarmes podem defendel-o contra as interrogações indiscretas. Dirigem-se ainda ás testemunhas, que não são protegidas de modo algum contria as solicitações, e assistimos a este espectaculo singular que, antes de ser a testemunha chamada á presença do magistrado, já foi ouvida por um, dois, tres ou mais reporters, que vão levar ao seu jornal, sem garantia alguma de exactidão, o que podem arrancar ás testemunhas por suas importunações.

Quero crer, continúa, que é sem má intenção que a sua linguagem pode ser alterada; mas, a memoria é fal. livel, e não é de duvidar que inexactidões sejam frequentemente commettidas. E', com effeito, muito menos o pro- 
prio depoimento do que a impressão pessoal que o reporters pode colher, que se traduz na sua narrativa. São, ao menos, sem inconveniente taes indiscreções? Quem o ousará sustentar? Não comprehendeis que actos de justiça, assim relatados, o são mais frequentemente com a impressão de que estão animados, sobre o fundo da questão, aquelles que os referem; que, assim, se encontram espalhados pelo publico elementos de apreciação inventados e que podem crear alternativamente os mais desagradaveis preconceitos, não só em relação ao accusado, como tambem em relação á accusação?

Precisando depois os factos que motivaram estas observações, recordou o senador Bevenger que, recentemente, em Versailles, uma accusada, presa preventivamente, tinha sido entrevistada quando a transferiam da prisão para o gabinete do juiz de instrucção; e, o que é mais grave, nesse mesmo processo, um dos jornaes parisienses, mais lidos, publicou uma photographia representando o gabinete, a propria scena do interrogatorio dos accusados: alli se veem, em pessoa, os dois accusados, o magistrado em sua curul, interrogando-os, o escrivão e o advogado. E accrescenta: "Si semelhantes praticas devessem se perpetuar, eu, que sempre fui partidario da instruçẽão secreta, principalmente depois que a lei de 1897 deu á defesa novas garantias, prefereria o systema inglez de instrucção franca, contradictoria e fiscalizada pela presença do publico, a esta publicidade illegal e viciada que hoje temos":

O ministro da Justiça, informa a Revista PeniTENCIARIA, recordou que havia recentemente ordenado medidas contra os jornaes que publicaram um certo numero de peças dos autos do processo Syveton e tratou de averiguar como se puderam dar taes indiscreções.

Segundo Rafael Rougier, professor da Escola Superior de Direito de Alger, o debate alli continúa a ser 
regido de accordo com o novo Codigo italiano de processo penal, pelo PRINCIPIO DA PUbliCidade. As portas do pretorio, francamente abertas, deixarão entrar todo mundo; mas, o projecto especifica que é prohibido reservar logares, a não ser para as pessoas cuja presença é necessaria e aos representantes da imprensa.

A inserção de tão insignificante detalhe em um Codigo, diz elle, mostra toda a gravidade de um mal para entravar os progressos, no qual não acha o legislador que seja demasiada a sua intervenção. Ella tende a impedir a renovação dos escandalos que, em cada processo sensacional, convertem o jury em sala de espectaculos, com a distribuição de ingressos de favor, açambarcamento dos logares reservados, e ah! tambem muitas vezes, com a transformação dos magistrados, das testemunhas e dos accusados em actores, preoccupados em produzir effeito Primitivamente, o projecto ia alem neste caminho, attendendo francamente a que, si a publicidade dos debates é uma garantia indispensavel para o accusado, a publicidade illimitada é, para o publico, não exemplar, mas desmoralizadora. Elle excluia da audiencia os menores de 18 annos e as pessoas sem qualificação, em busca, quer de emoções, quer de um complemento de educação profissional. Como no Codigo actual, o principio da publicidade admitte a restricção do huis-clos; e, como razão de auctorizar esta medida, o projecto accrescenta á preoccupação de ordem publica e dos bons costumes, o interesse do Estado e do inculpado. E', diz Rougier, uma tendencia perigosa. Si não é possivel deixar de approvar a disposição que permitte julgar de portas fechadas o menor (quando ha co-réos maiores de 18 annos), cujo futuro cumpre, antes de tudo salvaguardar, comprehende-se menos que o direito de reclamar o segredo da audiencia seja concedido ao accusado, sob o pretexto de que a ambiencia de uma sala hostil pode influir sobre o espirito do juiz; ou á 
parte civil, que teme que o debate prejudique o renome e a honra da sua familia. No primeiro caso, para evitar um perigo imaginario, a medida vae crear um perigo mui real. $\mathrm{Si}$, como suppõe o parecer, o espirito publico está prevenido contra um accusado, as manifestações da multidão á entrada ou á sahida, os ataques da imprensa, etc., podem actuar bem mais sobre os espiritos do que um barulho na audiencia, facilmente reprimivel por um presidente energico, como se deu no processo Zola. E, ao contrario, como esperar que se desarme a hostilidade das massas, deante de uma justificação fèita ás occultas?

Em um interessante estudo sobre a policia das audiencias nas causas sensacionaes, provocado por certas scenas de tal forma escandalosas que justamente emocionaram a opinião publica

"Il a paru veritablement indecent que le pretoire devint une salle de spectacle, où une foule elegante, mais irrespectueuse, mele á la voix de la Justice ses manifestations intempestives et ses rumeurs passionées"

Georges Hounorat diz: (lê)

"Certes je n'aît point l'intention de critiquer le moins du monde LA PUBLICITÉ DES AUDIENCES, QUi EST UNE Garantie de JUSTICE INDEPENDANTE.

L'audience doit être publique, c'est certain; LA PUbLICITÉ DES DEBATS DOIT ETRE ASSURÉE, c'est indiscutable et indispensable."

$O$ facto a que a principio me referi, narrado por Maxime du Camp, não ficou isolado. A historia se repete Ao iniciarem-se os debates do processo Renard, o presidente do tribunal do Sena teve o cuidado de prevenir os assistentes de que certos detalhes poderiam offender ouvidos pudicos; mas, em pura perda, porque ninguem com isso se incommodou. 
Hoje mesmo, li num dos diarios desta capital o seguinte telegramma da Allemanha: (lê) "O assassino Hermann, que está sendo julgado aqui, pediu ao presidente do Tribunal que mandasse sair do recinto as senhoras, visto sentir-se envergonhado por ter de narrar detalhes do seu crime em presença das mesmas. $O$ juiz declarou que não tinha poderes para obrigar as senhoras a abandonarem a sala, a menos que o quizessem fazer voluntariamente. Consultada a assistencia, nenhuma das senhoras presentes se moveu!

Foi, talvez, por essas e outras que o jury d'Indre et Lorie encontrou um meio, talvez excessivo, no conceito da Revista Penitenciaria, de impedir que as audiencias criminaes se transformem para um publico avido de emoções em uma especie de representação dramatica, isto é, que só sejam admittidas no recinto das sessões do jury as pessoas que apresentarem o seu diploma de eleitor.

Mas, com o suffragio universal ou generalizado, como temos, em que é eleitor todo brasileiro maior, sabendo ler e escrever, sem attenção ao seu criterio e moralidade, e em que é jurado todo eleitor, evitar-se-á por ventura que. como dizia Aramburu y Zuloaga:

"Se convierta las salas de audiencia en teatros gratuitos donde se representam escenas de comedia y aum de farsa en perjuicio de la verdad sencilla y de la justicia austera?" ( $L a$ nueva ciencia penal, pag. 286.)

Como correm as coisas na Italia?

Ouçamos o já citado prof. Puglia: (lê)

"La istruzione vera, diretta, della prova penal si compie nel publico giudizio; ivi nella lotta della parti; sotTo IL CONTROLLo DELla PUbLicitá la concienza sociale attinge direttamente della sua legitima fonte la propria convinzione della innocenza o sulla culpabilitá del 
citadino inviato in giudizio. Oralitá, PUblicitá e contradittorio sono le tre condizione che assicurano nei popoli civili la legitimitá e legalitá dei giudizio."

$\mathrm{E}$, accrescenta: (lê)

"Notizi inoltre, che essendo il reato una infrazione dell'ordine giuridico, ed appartenendo la esecuzione di esso alla societá la PUBLICITÁ É CARATTERE INTRINSECO del procedimento penale, che ha per fine la reintegrazione dell'ordine giuridico infranto." (pag. 19)

O professor Tolomei, salientando os uteis resultados da publicidade dos actos que constituem o juizo penal, observa que com ella se obtem:

a) un controllo del publico all'esatezza del procedimento;

b) un mezzo di tranquillare la coscienza comune che si fa la giustizia;

c) una prova che le leggi hanno la loro esecuzione;

d) una efficace cooperazione allo scopo della pena col dimonstrare ai malintenzionati che al reato tengono dietro la persecuzione e la pena."

E' verdade, diz finalmente Puglia, que contra a publicidade dos debates se teem levantado asperas accusações e ainda hoje assim procedem os sequazes da escola criminal positiva, especialmente pela consideração de que os ociosos e perversos, frequentando as audiencias, se educam e apprendem os meios de escapar facilmente ás mãos da justiça; mas, nós

"RITENIA vo CHE LA PUbLicitá SIA CARATTERE INTRINSECO DEL PROCEDIMENTo PENALE e que só se poderá discutir o modo de a regular praticamente. (op. cit. pag. 20) 
La PUblicitá, poi, DEI DibatTinenti É LA MAGGIORÊ DELLA GUARENTIGIE e perció l'art 268 dei vigente codice prescrive che la udienze avanti le corti, i tribunali ed i pretori sono publiche SOTTO PENA DI NULLITÁ; disposizione in armonia all'art 72 dello Statuto. Ed é perció che il giudizio penale deve celebrarsi in aula capace di accogliere un buon numero di persone e COLLÃ PORTE DISCHIUSE AL PUBLICO.

“LA PUblicitá DEI DIbATIMENTI É gÃRANZiA DI UNA RETTA AMMINISTRAZIONE DELLA GIUSTIZIA, perché, non solo impedisce che in qualsivo glia modo si violano i diritti dei giudicabili con atti arbitrarie, ma anche é di freno in non pochi casi pei testimoni, che sarebbero disposti ad alterare la veritá dei fatti, intorno cui son chiamate a deporre. Colla publicitá dei dibatimenti ogni, cittadino vive sicuro che giustizia si fá, ne teme d'ingani o di mistificazioni.

"Alla publicitá del dibatimento si fa eccezione nel caso in cui essa possa renscire pericolosa alla morale ed al buon ordine. E l'art. 268, al. $2 .^{\circ}$, dispone che, quando puó avvenire, la corte, il tribunale ed il pretore portrá, sia d'ufficio, sia sulla richiesta del pubblico Ministero, ordinare che il dibatimento abbia luoco a porte chiuse

E', como se vê, uma medida facultativa, a que o pretor, o tribunal ou a côrte são livres de recorrer ou não: mas, mesmo assim

"l'mputato ed il suo difensore possono, se credono non concorrere ragion di moralitá e di ordine, elevare protesta contro l'ordinanza

Serão, porventura, taes protestos platonicos e destinados unicamente a armar effeito? 
Enfim

"L'oralitá del dibattimento é poi intimamente CONNÊSSA COLLA PUBLICITÁ e diretti al diziario."

fine di riuscire allo accertamento del vero giu-

Ouçamos agora o prof. Luigi Lucchini, em seus Elementi di procedura penale, pag. 307: (lê)

"Vi sono alcuni principi o norme d'indole generale e FONDAMENTALE che devono regolare il dibattimento e della cui osservanza, piena o meno piena, si caratterizza l'indirizzo proprio della doutrina e della legge. De norme e le disposizione particolari non ne sono poi che altretanti corollari e svolgimenti.

FRA TUTTE LE GUARENTIGIE PROCESSUALE, LA MAgGIORE É CerTaMENTE QUELLA DELla PUBLICITÁ

"La veritá e la giustizia non devono e non possono avere segreti ne misteri. E' um errore, un prejudizio il credere che la publicitá degli atti possa comprometterne l'efficacia e la veridictá

"In fine, dove il procedimento s'avolga nel segreto e nel mistero, ivi entra e domina il sospetto de l'abuzzo, dell'arbitrio, della frode; e la giustizia ha sopratutto bisogno della luce, perché nella coscienza del giudice si rispechi la coscienza diella societá, condizione indispensabile onde il procedimento penale raggiunga tutti $i$ suoi atti ed umanissimi fini

Come il rito é la sintesi degli altri elementi processuali, cosi nella suprema garanzia della sua publicitá devono rifulgere di maggior luce le guarentizie ritenute necessarie rispetto a ognuno di essi elementi. 
E' infatti con la publicitá degli atti che si rebadisce e rafferma l'interesse generale della societá all'esercizio dell'azione penale, che nella volutazione delle prove si rende sopra ogni altro sistema rassicurante quello che lo affida al libero e razionale convincimento del giudice, e che eccelle in tutta la sua maestá l'independenza del magistrato, fiancheggiato della sua manifesta responsabilitá.

FaUtori della publicitá anche NEL'isTRUTTORIA, intesa e disciplinata piú ragionalmente di quello che ora no sia, TANTo PIÚ DoBBIAMO OMMETTERNE, E SENZA RESTRIZIONE, IL PRINCIPIO NEL DIBATTIMENTO.

Fala agora o grande Pessino:

“ il giudizio propriamente detto nella legge vigente italiana presuppone la sussistenza di una accusa formale che debbe essere disanimatia. Questa desanima debbe avvere, guisto l'e lemento accusatorio: tre condizione FONDÃMENTALI, cioé la contradizione delle parti interessate, l'oralitá dell'esame, LA PUbLicitá (dibattimento orale e publico)

c) La discussione contradittoria ed orale debbe esser fatta, non solo in presenza del giudice legale chiamato a decidere la causa penale, ma debbe esser fatta innanzi alla societá umana, merce la forma della publicitá (nella sala delle udienze e con le porte dischiuse al pubblico). Imperoché il giudice legale é rapresentante giuridico di un altro giudice, cioé della pubblica opinione; e la coscienza del paese debbe poter suggettare col suo giudizio morale la autoritá del giudizio legale." (Discorsi varii, vol. 4, p. 71-'72) 
Foi justamente a proposito desta questão que se deu, ha tempos, na Italia, uma viva e interessante polemica, verdadeira lucta de gigantes, entre o insigne Cavagnari e o não menos notavel E. Florian, que passo a resumir.

Num artigo intitulado - la publicitá dei dibatimenti e l'educazione del carattere, inserto na Ecuola Positiva 1893, ps. 216 e seguintes, dizia o primeiro: (lê)

"La publictá dei giudizi, la cosi detta giustizia popolare dei giurati, sono prejudizi ed assurdi giuridici. Ebbero valore come espedienti politici, dai quali i nostri tempi non sentono piú il bisogno, perché preoccupati della questione economica e della questione educativa, perché giá prossimi alla convizione che urge sopratutto di formare il carattere individuale e sociale.

La suppressione della publicitá peró sará relativa, non potendosi escludere gli studiosi, coloro che professano l'avvocatura, i psichiatri, ecc. ecc., come non si escludano dai teatri anatomici i medici e gli studenti. Anzi la loro presenza, con quelle pochi giornalisti ammessi, servirá di sindacato e di controllo, sostituendo in modo migliore il pubblico degli sfaccendati e dei tirocinanti del delitto. Il dibattimento procederá piú spiccio, i testimoni saranno piú sinceri, gli oratori dell'accusa e della difeza, che parlano spesso pel pubblico, di cui ricercano il plauso, saranno piú concisi e piú temperati, e anch'essi piú sinceri

"Se la publicitá dei dibattimenti deve abolirsi per non ridestare emozioni che dovrebbero lasciarsi nel fondo piú basso dell'animo, per non creare accanto all'individuo delinquente giudicabile, la folla delinquente provocatrice e complice, per la stessa ragione si dovrebhe vietare 
la publicazione dei particolari piú minuti dei delitti piú gravi e dei suicidi. Se quando avviene un delitto in un luoco, noi consideriamo nocivo la notizia e l'emozione per quei pochi che debono necessariamente saperlo, che diremmo poi quando pensiamo che colla pubdocazione in giornali si ha una propagazione della stessa notizia e dell-emozione?

"Non é questo un estendere l'aria morbigena del delitto? non é questo un allargarne l'influenza come un contagio epidemico? E' un fatto incontestabile che $i$ delitti avvengono per suggestione, come i fatti eroici; e perché propalarne, illustrarne la notizia, ingrandirne gli impulsi?

"Non é una nuova sorgente di corruzione, non é un ulteriore attentato alla publica moralitá, non un formidabile ostacolo all'educazione sociale?

"Questa diffusione alimenta una fonte importantissima della delinquenza: l'imitazione, che ha tanto peso nelle umane azione, e l'émulazione che ne é una forma particolare. Vi sono individui cosi organicamente predisposti al delitto pei quali il triste esemplo altrui é la goccia che fa traboccare il vaso; ci sono individui che complacentisi della delinquenza ne seguano le vicende e le forme come le donne la moda; sicché un fatto audace non mai accaduto, li accende, li riconduce al delito, ponendoli in preda a triste spirito de emulazione. "I fondatori della nuova scuola criminale non hanno formulato precise conclusioni in ordine alla publicitá delle udienze. Il Lombroso peró suggurisce, a riguardo delle assise, che si dovrebbe limitare il numero e la 
qualitá degli accorrenti alle corti di assise, non permettendo l'accesso ai minorenni, ai sorvegliati o sospeti, evitandosi in tal modo le scene scandalose che mutano gli assise in un teatro, ed ah! spesso in un ritrovo ancor meno coretto e sempre in una specie di scuola pratica d'immoralitá e di incitamento alla vanitá dei criminali

Em resposta a Covagnari, Florian, no interessante estudo que tem por titulo - Pel diritto di conoscere $i$ fatti criminosi - depois de aconselhar certas reformas de accordo com a escola positiva, diz: (lê)

"Fatte quelle riforme, ed io credo che la publicitá dei dibatlimenti penali, lunghi dall' essere fomite di immoralitá, si mostrebbe fatore di moralitá e di educazione. Nelle aule della giustizia si vedrebbero puniti, infatti, dei delinquenti veri, degli elementi antisociali ed il favore popolare alleggerabbe attorno all-opera dei giudice. Il carattere si aducherebbe attorno all'opera dei giudice. Il carattere si educherebbe serio, sanno, positivo; giacché il processo non sarebbe, come ora, unabile edificio di parole, ma un'analisi scientifica di fatti e di datti scientificamente accertati. Farse, contrariamente lal'opinione dei piú, la curiositá pubblica ed il concorso, non sarebbero scemati; sarebbe invece probabilmente mutato il genero dell'uditorio. I criminali non avrebbero di che soddisfare la vanitá loro ed imparerebbe ció che non imparono ora, come la societá agisce sul serio contra quelli che la offendano.

"La causa quindi del danno é piú addentro: nell'organismo processuale piú che nel din- 
torno della publicitá, prima bisogna riformare quel'organismo. Allora da publicitá cessará di essere una forma di quai, e non si potrá piú invocarne a soppressione in nome dell'educazione sociale.

La morbosa curiositá del pubblico non dipende, rigorosamente, della publicitá dei processi; forse é piú vero il contrario, che tale curiositá ha generato la teatralitá dei processi, suggestionando, per cosi dire, giudice ed oratori, giudice ed accusati

"Ben diceva Schäffle che la publicitá é una necessitá sociale-psicologica. Se cosi é, sopprimento la publicitá non si sopprime la curiositá morbosa la qualle trovrebbe altre vie nelle gerali espandersi; e poiché non il mezzo onde si manifesta, ma la curiositá morbosa per se produce danno all'educazione, ne viene che quella soppressione non recherebbe alcun benefizio alla causa dell'educazione. Del resto, l'abolizione delle udienze penali publiche non raggiungerebbe lo scopo; giacché noi vediamo con quanto zelo si esercita la curiositá morbosa attorno di processi che si tengono a porte chiuse, dei quali poi si spandon subito per la cittá e si conoscono i piiú minuti particolari! Altra riforme occorrano dunque per estirpare la curiositá morbosa."

Florian declara-se de accordo com Cavagnari na repulsa energica aos chamados grandes principios, que, na verdade, não passam de - metafisica rampollata da intelleti olimplici - mas do mesmo se afasta, quando julga inutil a publicidade como garantia do accusado e prova de fiscalização. E continúa (lê) 
"ritenuta peró la unessione fra la divulgazione del resoconto per le stampe e le forme storiche del processo; affermato, come noi abbiamo, che pubblico debe essere il dibattimento - ne deriva logicamente quella divulgazione, la quale é della publicitá consequenza naturale e quasi necessario complemento. Né vale il dire che in "tal guiza si spargono i germi dell'immoralitá e della delinquenza", non é questo il solo lato della questione. La criminalitá é fenomeno sociale che tutti debbono conoscere; al quale tutti debbono interessarsi, perché tocca gli interessi di tutti; perché rode e mina la fondamenta stessa sul cui la societá si erige. Ognuno poi ha il diritto di conoscere quali sieno $\mathrm{i}$ delinquenti per eventualmente guardarsene.

Inoltra non bisogna dimenticare i servizi inestimabili che la stampa rende in altri campi, nel campo del controllo, come organo delle vavie correnti della publica opinione; essa é una instituzione di civilitá, onde il Pessina recentemente se dava dignitá di eforatro moralee superiore a tutti. Ma essa ha altresi il compito delle informazione, che debe adempiere come condizione essenziale per poter vivere ed esercitare il primo. Ora, si cosi é, bisogna bene consetire alla stampa il mezzo di vivere e di svilupparsi, perché di poesia e di belle parole non vive di certo: quindi bisogna permetterle di fare la cronaca ampla, estesa, minuziosa, che interessa la parte maggiore dei lettori; ed elemento precipuo di questa cronaca sono appunto i dibattimenti penali. Né si ha temore che $\mathrm{i}$ giornali gonfino e svisno quanto si svolge nell'aula della giustizia, giacché in tal caso sorgerebbe il diritto di sospendere o seques- 
tare $\mathrm{i}$ loro resoconti non esatti e non redatti in buona fede e di funirne i compilatori; cesserebbe allora quel-l'animo narrandi, che dal punto di vista soggetivo, giustifica la publicazione dei resoconti giudiziari."

Refutando a terceira opinião, sustentada por Sergi, Cavagnari, Frola, Stivanello, Semmola e outros, segundo os quaes deveria ser prohibida a publicação de noticias e dos detalhes dos crimes, logo após a sua pratica, accrescenta: (lê)

"Questo voto generoso si conputa facilmente dicendo ch'é impossibile di effectuarlo nelle condizioni psicologiche attuali della societá e dell'individuo. L'aviditá con cui quelle notizi si leggono dimostra, da un lato, che il divieto ucciderebbe il giornale, al quale piú che articoli di fondo e rassegne scientifiche si chiedono notizie emozionanti e riccheza di cronaca - dall'altro, che non raggiungerebbe lo scopo, giácché quelle notizie e quei particolari si diffonrebbero di bocca in bocca e spargerebbero egualmente fra il popolo, producendo anche mali maggiori che adesso, perché esagerati dalla fantasia e dal dubbio. Questi tristi effeti, diminuzione della stampa e maggiore curiositá delle narrazioni di delitti comuni, alla seconda e alla terza qu'estione, mostrano come, sopprimento la publicitá delle udienze, si avvrebbe una somma di inconvenienti maggiori che adesso."

Dicono che la publicitá dei giudizi e la divolgazione dei reati corrompono il carattere, dei quali impediscon in gran parte la sana educazione; sono fonte copiose d'immoralitá. Anzitutto, 
peró, va notato che l'immoralitá procede da un cumulo ben grande di cause d'ordine individuale o sociale, d'ordine atavistico ed occasionale: di essa, dunque, la publicitá e la divolgazione non posano essere che fattori assai tenuf. $\mathrm{E}$ che sia cosi, ce ne ammaestra la storia; giacché noi vediamo inondata della piú ampla corruzione l'epoca in cui i processi si svolgevano in segreto, e di girnali non ce n'evano affatto o ben pochi e diversamente compilati da quelli odierni. Citiamo, a cazione d'esempio, l'epoca imperale romana della decadenza, in cui andavano ognor piú introducendosi e sviluppandosi gli elementi del processo inquisitorio, mentre da piú larga corruzione si spandeva $\mathrm{n}$ Roma e nelle provincie; citiamo il nostro einquecento, splendido di sapienza, di coltura ed insieme deturpato da oribile depravazione. Eppure in quel cecolo memorabile dominava sovrano il processo inquisitorio!

"Dunque la corruzione non deriva da quelle manifestazioni di publicitá che in minima parte.

Ma v'ha di piú. La soppressione di quelle forme di publcitá migliorrerebbe i costumi? A parte che, come abbiamo visto, non raggiungerebbe lo scopo di tenere i delitti celatti celati ai piú, é intuitivo che la rigenerazione della coscienza, che l'educazione del carattere debbono procedere da riforme sociali ben altrimenti organiche?

Troppo grande é il fine, troppo meschino il mezzo.

E vogliano vedere quale effeto immediato avrebbe la soppressione delle forme di publicitá 
prima menzionata? Per esse si favorirebbe quel sistema d'ipocrisia e di mensogna, che giá é tanto diffuso: si moltipliccherebbero quei caratteri servili incerti, duttili che pullulano nella societá borghese, si estenderebbe la funesta consuetudine di tacere il vero: mentre di carattere franchi, veritieri, aferti abbiamo tanto bisogno perché senza di essi non c'é progresso reale come dimonstra il Sergi, in alcune splendide pagine del suo libro. Se il vizio di nascondere il vero é eretto a sistema dell'organizazione pubblica, non lo imiterano i privati ? E poi questa certezza que la propria mala azione, che il proprio reato non viene conosciuta della gran massa dei concittadini, credete forse che incorragi gli incerti, che non eciti gli uomini i quali per delinquere attendono l'occasione e la spinta? Dimenticate l'efficacia del controllo della pubblica opinione, riconosciuta da Bentham, da Romagnosi, da Filangîeri, da Ellero e da tanti altri illustri pensatori.

IL SISTEMA PROHIBITIVO DUNQUE PRODUREBBE MALI PROPRI, SENZA RAGGIUNGERE LO SCOPO DI TOGLIERNE ALTRI, O TOGLIENDONE ASSAI POCCHI.

Miriamo all'educazione del carattere, ma miriamo anche all'overtá ed alla sinceritá sociale, senza delle quali non'ha carattere pieno ed integro. Per questa sinceritá, la notizia dei reati, la publicitá delle udienze e la divulgazione dei resoconti penali sono necessarie. Se esse producano dei mali, non precipitiamo il giudizio sino a proporre di sopprimerle; ma corrigiamole, per diminuirne i tristi effeti e sopratutto contrapponiamo loro forme di educazione sana ed ordi- 
nata alla solidarietá umana, facendosi anzi di esse un istromento per mostrare la bruttura ed il damno dell'immoralitá e del vizio e per contrapporvi la belleza e la utilitá delle generose virtú sociale!"

Respondendo a Florian disse, entre outras coisas, Cavagnari: $(l \hat{e})$

"In quanto alla pubblicazione dei resoconti giudiziari, per mezzo dei giornali, io non sono contrario, anzi la propugno come una consequenza logica e immediata del principio di ammettere alle udienze penali un certo numero de giornalisti. Desiderai peró che anch'essa fosse sottoposta a qualche regola limitata, perché convengo pienamente col Sergi e col Lombroso che essa serve mirabilmente alla diffuzione dell'influenza morbigena della criminalitá, facendo agire le forze potenti dell'imitazione e della varietá che non di rado abbatono le ultime resistenze della orientá debili ed incerte. E' assai difficile conoscere sino a qual punto il contagio che si diffonde a mezzo dei resoconti giudiziari; ma si puó argomentare per analogia della grande influenza che la cognizione dei suicidi ha sull'animo da quelli che sono bersagliati da male fisici o morali, o affeti da quel morbo terribile ch'é il tedio della vita, o accesi della varietá di far parlare e scrivere di sé.

Schema il valore della vita nell'opinione dei moralmente o fisicamente deboli, i quali nell'esempio altrui trovano l'impulso decisivo a trancare la loro esistenza, ed aprendono il mezzo piú pronto e piú sicuro e piu streongante per effetuare il dsperato proposito." 
Em sua - Theorie des garanties constitutionelles, pag. 180, vol. 2..$^{\circ}$ Cherbuliez diz: (lê) "No exercicio das funç̧ões judiciarias encontramos tres operaçóes preparatorias: o debate, a deliberação, a votação. E' preciso, para o publico conheceí os factos sobre os quaes se baseia a decisão, as formas que foram observadas para constatar taes facto e a propria decisão. E' pois, aos DEBATES e á sentença que deve estar ligada a PUBLICIDADE; então, como a lei que o juiz interpreta é tambem conhecida, todos os elementos necessarios para apreciar as sentenças judiciarias estarão nas mãos do publico."

E, para rematar este ponto, não preciso mais do que invocar a assaz reconhecida auctoridade de João Barbalho, o eminente commentador do nosso acto fundamental, e que, á pagina 338 dos seus Commentarios, diz: (lê)

"São caracteristicos do Tribunal do Jury: II, quanto ao funccionamento: a) a incommunicabilidade dos jurados com pessoas extranhas ao conselho, para evitar suggestóes alheias; b) ALLEgaçõEs e provas da accusação e defesa PRoDUZIDAS PUbLiCamente perante elle; c) attribuição de julgarem estes jurados segundo sua consciencia, e d) irresponsabilidade pelo voto emittido contra ou a favor do réo. Respeitados estes caracteristicos, podem as legislaturas dos Estados alterar a lei commum do Jury."

Eis ahi! Mais claro é impossivel!

Admittamos, porem, para argumentar, que a publicidade não seja fundamental, essencial nos debates perante o Jury; que o art. $2 .^{\circ}$ do projecto em discussão seja constitucional, lograremos com elle alcançar a meta dos seus auctores, isto é, tornar secretas as inconveniencias do processo, a infelicidade da victima, os manejos e audacia do criminoso em seus minimos detalhes? Absolutamente, não! porque entre nós não se dá, como em Athe- 
nas, onde, para ser dicasta, era preciso ser maior de 30 annos, ter uma vida irreprehensivel e nada dever ao thesouro publico.

Aqui, entre nós, onde os jurados são os eleitores e os eleitores são - tout le monde et son pére - de que servirá essa reserva imposta pelo projecto, quando os proprios do conselho serão os primeiros a ir revelar e commentar em publico todas as peripecias $d_{0}$ processo, com a aggravante de fazel-o sem criterio algum, muitas vezes de modo errado, adulterado até, sinão pela propria incapacidade, pelo espirito ou máo vezo da maledicencia?

Tinha, por sem duvida, razão Stuart-Mill, quando dizia que nấo se podem curar as chagas sociaes sinão descobrindo-as completamente.

E', com effeito, lamentavel a sorte de uma moça, victima das manobras indecorosas de devassos; é doloroso ver a sua desgraça exposta ás chacotas de defensores sem escrupulos; mas, contra isto LEGEM HABEMUS; está na alçada do presidente do tribunal regular a policia das sessões, chamando á ordem os que ella se desviarem ( $\$ 4$., art. 45 do Codigo do Processo Criminal; $\$ 7 .^{\circ}$ do art. 200 do Reg. $n .^{\circ} 120$ de 31 de Janeiro de 1842). Mas, quando não tivessemos providencias efficazes contra os excessos de linguagem que tiram ao tribunal o caracter de auctoridade que tanto lhe convem, mesmo assim não seria o caso de recorrer ao segredo dos debates. 0 exemplo é alguma coisa; e essa penosissima situação em que ficaria a victima, dada a publicidade, servirá ao menos de preventivo contra a descahida de outras que, melhor avisadas, saberão tomar suas precauções para evitar egual perigo e egual vexame.

Si o espectaculo das execuções capitaes exerce uma influencia nefasta, principalmente sobre os tarados, suggestionando-os para a pratica do mesmo mal, a suggestão 
do jury, a idéa de se ver exposta á risota e aos commentarios perversos não exercerá tambem uma influencia suggestiva em sentido inverso? Quantas cahem, porque ignoram o mal? Mas, si não o ignorando, avisadas, se deixam seduzir, de quem a culpa? Da publicidade dos debates? Absolutamente não!

Entre nós principalmente as sessões do jury são quasi ou nada frequentadas por mulheres. No meu tirocinio de ministerio publico e de advocacia, mui poucas vezes divisei, entre os assistentes e curiosos do pretorio, representantes do sexo fraco, e isso mesmo quando se tratava de causas sensacionaes, mas em que não entrava em jogo o pudor.

De resto, nestes crimes não cabe procedimento official, a não ser quando a offendida é miseravel. Porque? Porque o legislador entendeu que a sociedade não se deve immiscuir em coisas que dizem respeito e primeiro interessam ao chefe da familia; a acção do ministerio publico é meramente accessoria e destinada como que a reforçar a acção dos queixosos. Mas, si o chefe da familia prefere trazer a publico debate a honra ultrajada dos seus, a sociedade não tem o direito de lhe tolher a acção, tanto mais que della poderão resultar para outros effeitos preventivos a que ha pouco me referi.

De que servirá qualquer publicação no sentido do projecto, quando a imprensa, que tudo divulga, se infiltra por todos os lares, levando noticias muitas vezes tendenciosas, exaggeradas, não por certo com intuito de prejudicar a quem quer que seja, mas pelo desejo de furar os collegas e causar sensação?

Mas, como diz Proal, a ausencia de má intenção não basta para impedir um livro de ser malfazejo e tornar o seu auctor irresponsavel do mal, que produziu. Ha em litteratura, como em direito penal, delictos de homicidio voluntario e de homicidio por imprudencia. Matar um 
homem por negligencia, inobservancia dos regulamentos, é uma culpa que a lei mui justamente pune. A ausencia de intenção criminosa não exclue a responsabilidade moral, nem mesmo a penal. $\mathrm{O}$ homem que vive em sociedade tem o dever de se preoccupar com as consequencias dos seus actos, e é um culpado si, por sua negligencia ou impericia, causa a morte de um dos seus concidadãos. Conheci um proprietario que, para conservar o seu vinho, nelle addicionou uma substancia nociva, que envenenou os que o beberam. E' claro que elle não teve a intenção de matalos e, entretanto, foi condemnado por homicidio involuntario. Assim, o escriptor que inclue em suas narrativas sophismas que falseiam o espirito e que conduzem os leitores ao suicidio, ao adulterio, ao crime, commette um acto culposo pelo qual é responsavel.

E o theatro, onde "os máos exemplos são contagiosos" e as representações fingidas causam crimes verdadeiros, onde, como diz Racine

"Le feu des passions saisit l'especiateur:

Il aime, il haît, il pleure, et lui même est acteur?"

De que servirá essa precaução contra os raros processos que entre nós apparecem, quando ahi está ao alcance de todos, mulheres e creanças, a tela cinemathographica, que produz ao vivo todas as perversidades e depravações humanas, tudo quanto a sociedade tem de reprovavel e escandaloso, tudo quanto os costumes teem de asqueroso e despresivel?

Na Italia, o governo, á vista da desfaçatez dos films, fez baixar os decretos de 9 de outubro de 1919 e 22 de abril de 1920, instituindo a censura cinemathographica.

Foi commentando esses decretos que a Revista Penale disse: (lê) "Pensamos que a censura deveria começar sobre a arte dos auctores, empresarios e operadores de producções cinemathographicas - arte espalhada e tão mi- 
seravelmente representada na Italia, si a compararmos com a verdadeira arte cinemathographica, tal como existe em França. Entre nós, em summa, na maior parte dos casos, não se tem outro fim: excitar, pelos meios os mais vulgares e os mais deslavados, o instincto erotico dos espectadores."

E o theatro, "que agita todas as paixões, tanto as mais nobres, como as mais baixas, dá licções de dedicação e de patriotismo, como dá licções de odio e de vingança: ensina a sacrificar o amor ao dever, como o dever ao amor."

O theatro que, "assim como pode ser uma escola de bom gosto, criticando as estravagancias das sabichonas, dos pedantes, dos marquezes vaidosos, dos medicos ignorantes, dos advogados palradores, pode tornar-se tambem uma escola de grosserias e cynismo, ensinando ao povo a giria dos ladrões, a desfaçatez das cortezãs e das adulteras. Nada é mais contagioso que os bons e os máos exemplos dados pelo theatro, nada se propaga com mais facilidade do que as maximas sabias ou perversas que espalha pelo publico."

"A acção do theatro é ainda maior sobre as paixões do que sobre as idéas, porque as paixões são a alma do theatro, e, para interessar os espectadores, os heróes do theatro querem ser apaixonados, amorosos, ciumentos, ambiciosos, vingativos. Si o povo assiste a dramas patrioticos, torna-se patriota; si se lhe préga o fanatismo, torna-se fanatico si se lhe declamam tiradas anti-sociaes, torna-se revoltoso. Em uma palavra, o theatro, que não passa de um prazer litterario para os espiritos cultos, é para o povo uma escola de moralidade ou immoralidade, de patriotismo ou egoismo, de obediencia ás leis ou de revolta."

$\mathrm{E}$ os romances? De que servem todas as precauçóes contra a sessão do jury, quando á disposição de todo mundo ahi estão os romances e as novellas sobre assumptos im- 
moraes, com scenas picantes e mesmo indecentes, lidos francamente ou ás escondidas?

E' por isso que Proal, em sua notavel obra intitulada - Le crime et suicide passionels - diz, á pag. 407: (lê) "Procurando como magistrado as causas dos crimes passionaes tive muitas vezes occasião de constatar que taes crimes são imitações de romances, ou a litteratura em acção."

Legrand du Saule insurgiu indignado contra essa litteratura, que familiariza o publico com o crime e ergue uma especie de pedestal aos que comparecem perante o jury.

"Os romances judiciarios, prosegue Proal, que reproduzem a narrativa dos crimes celebres, são muito populares; são publicados em folhetins pelos pequenos jornaes a cinco centimos e penetram em toda parte. Annunciados pelos grandes cartazes coloridos, que representam uma scena de assassinato ou de deboche, familiarizam o espirito das creanças, das raparigas e das mulheres com idéas e imagens, que seria mais prudente.dellas afastar.

Sobre todos os muros de Pariz veem-se homens assassinados, creanças martyrisadias, mulheres mettidas em orgias. Todas estas imagens se gravam no cerebro dos transeuntes.

Os que conhecem a impressionabilidade do cerebro da criarça, o poder de um abalo moral, sabem que uma imagem lubrica pode perturbar profundamente a creança, principalmente a menina na época da puberdade. Já assignalei a influencia consideravel das primeiras leituras; as primeiras imagens teem ainda uma influencia mais profunda: impressionam muito mais que as palavras.

Si collocarmos na escola, nas ruas, bellas imagens representando assumptos historicos, patrioticos, religiosos e camprestres, fariamos passar ao espirito das creanças, sem esforço e somente pelos olhos, um ensino verdadeira- 
mente moral. Deixamos, ao contrario, ostensivamente, sobre todos os muros, nas vitrinas dos kiosques e das livrarias, imagens representando crimes de odio e crimes de luxuria, que constituem verdadeiros attentados á moralidade e ao pudor das creanças. Taes imagens gravam-se em seu cerebro e ahi deixam traços inapagaveis; mancham a sua imaginação e podem suscitar actos analogos."

Quem ignora a influencia enervante, diz Dechambre, em seu Diccionario de Medicina, das leituras eroticas, dos espectaculos e de certas reunióes mundanas, que sobrexcitam prematuramente os sentidos; apaixonam a imaginação e lançam as jovens nos braços de todas as aberrações dos sonhos romancescos, quando não os precipitam nos perigos do hysterismo?

E é por isso que Proal affirma ser preciso uma certa madureza de espirito e uma real força de caracter para reagir contra a influencia do meio, do exemplo e da leitura.

Será porventura, contagioso o espectaculo $\mathrm{d}_{\mathrm{o}}$ jury apenas nos crimes contra a honra? Quem o ousará affirmar? Mas, si o contagio e a suggestão se extendem a outros crimes, porque o segredo só para os primeiros?

Ora, si contra tudo isso ninguem se insurge, não se tomam precauçóes, para que ir viciar com uma reforma destas uma instituição que, si não é efficaz sob o ponto de vista da repressão, offerece, comtudo, outras vantagens, das quaes não é a menor a que dá ao povo o sentimento da sua soberania? Para que introduzir na lei preceitos hypocritas e regras que nem mesmo salvam as apparencias, quando, na França, pela voz de Corintin Guyho, se procura dilatar as attribuições dos jurados, tornandoos arbitros das penas?

Porque retirar á nossa democracia o direito e o goso de viver ás claras e procurar engasopar o publico com o segredo de :. Polichinelo? 
Eis ahi as razões do meu voto, que encontram inestimavel reforço nas seguintes palavra do mestre: $(l \hat{e})$

"Ma finché questa abolizione non é proposta e sancita per legge, riteniamo altrettanto doveroso rispetare l'istituto del giuri, cosi come della degge é chiamato a funzionare. E riteniamo sintoma di anarchia morale il ferire questo istituto a colpi di spillo, ora con un decreto che sotto parvenza di coordinare il nuovo Codice penale colle leggi esistenti ha sottratto al giuri la competenza di almeno la metá delle cause che il Codice di procedura gli affidava." (FERRI Difese penali, pag. 377 )

Tenho dito.

Vozes - Muito bem! Muito bem! 